\title{
Analysis of the Trade Cycle in the UK and its Relationship to the Business Cycle
}

\author{
$1^{*}$ Fitra Prasapawidya Purna, ${ }^{2}$ Ibrahim Sorie Kamara
}

Email : ${ }^{1}$ fitra.prasapa93@gmail.com, ${ }^{2}$ ibrahimsoriekamara216@gmail.com

Afiliation: ${ }^{1}$ Universitas Muhammadiyah Yogyakarta, Indonesia, ${ }^{2}$ Sierra Leone Civil Aviation Authority, Sierra Leone

* Corresponding Author

\begin{abstract}
This study aims to analyze the trade cycle in the UK and analyze its relationship to the business cycle. This study uses secondary quarter data in the form of exports, imports, and UK GDP from 1987 to 2016. Band-pass filter data filter method is used in this study to isolate shortterm cycles and assume an average growth of each variable. The results of this study indicate that the trade cycle in the UK has a medium-term cycle of around 2-4 years for both exports and imports. And there is a significant relationship between global economic events and movements in the trade cycle. Like in the early 2000s and late 2008. The relationship that exists in the cycle, especially the trade cycle between exports and imports, is found to be procyclical where the conditions are mutually exclusive. Meanwhile, between the trade cycle and the business cycle in the UK, there are many counter-cyclical situations where the relationship between the two cycles is inversely proportional. This is different from the findings of previous studies.
\end{abstract}

This is an open access article under the CC-BY-SA license.
Article history

Received 2021-10-03

Revised 2021-10-27

Accepted 2021-11-02

Keywords

Trading Cycle

Business Cycle

global economic

JEL Classification*:

$H 4, R 3, D 4$

\section{Introduction}

The world's economy moves in different cycles at each level. Starting from the household level, regional level, domestic, national and even international. One of the many moving cycles is the trade cycle, especially at the international level, which is symbolized by the value of a country's exports and imports. Countries that trade more will have a correlation with the business cycle (Giovanni et al, 2010) which is explained in the value of gross domestic product or GDP. So that the trade cycle has a close relationship with the business cycle itself. One area that has implemented policies related to strengthening international markets is Europe where they have established a forum for their scope called the European Union or EU. However, there is one country that is taking a different step, namely the UK. The British public held a referendum for Britain to leave the EU, which we eventually know as Brexit or Britain Exit. The referendum which 
was held on 23 June 2016 resulted in a decision that the UK would officially leave the EU from 29 March 2019.

According to Prasad (1999) knowing the causes of fluctuations in international trade is very important, especially from various perspectives for macroeconomic forecasting and is also a consideration for short-term domestic policies and international policy coordination. As well as a policy that occurs in a country can affect the output of their trade so here the researcher wants to discuss the trade cycle owned by the UK starting from its relationship with the world crisis and with the policies implemented by the country itself.

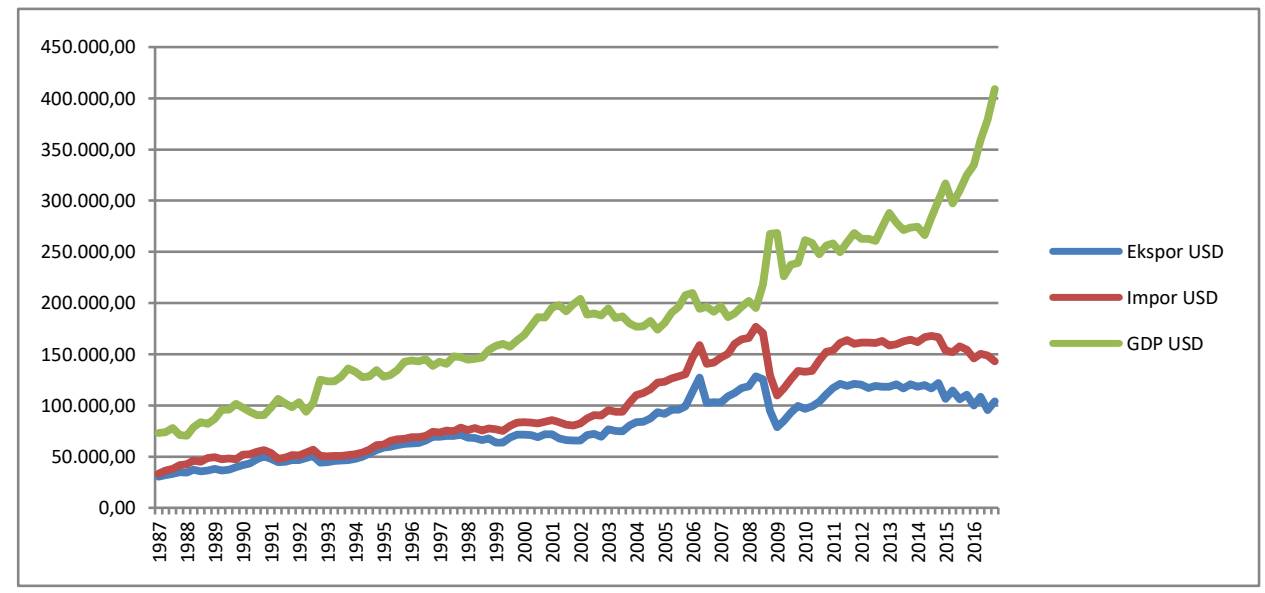

Sumber : International Monetary Fund diolah, 2017

Figure 1. Movement of Exports, Imports, and GDP of the UK for the period 1987-2016

If you look at Figure 1 regarding trade data held by the UK, it shows that the trade fluctuations occurred during the 2008 crisis that affected the global economy. But if you look at the business cycle owned by the UK, it tends to fluctuate and has a positive trend even though it is not too much of an influence from the state of its trade value, which fluctuates higher than the country's GDP value. Thus, the main contribution of this research is to prove the relationship between exports and imports with GDP where in some circumstances they are positively related and in some cases they are negatively related or even have no relationship.

\section{Literature Review}

The concept of the trade cycle itself is not much different from the business cycle because basically they are related. The business cycle is the most important basis for estimating indicators related to economic activity in a country. According to Mankiw (2006) and Queen et. al. (1993), what is meant by the business cycle is the most important basis for estimating indicators related to economic activity. The business cycle is basically obtained through two main components, namely trends and cycles. Trend is a movement that shows the general direction of development (up or down trend) in the long term. The business cycle is the movement of output fluctuations around a trend line. This cyclical movement can be repeated over a period of time (every five 
years, ten years, or more). The cyclical movement shows the state of the economy whether it is experiencing prosperity, recession, depression, or recovery. There are four stages in the business cycle, the first is expansion, which is a condition of economic recovery (recovery). At the time of expansion, economic growth seemed to start moving up. Economic activity is called expansion if there is an increase in at least two consecutive quarters. Second, the peak which is the peak point of economic activity that is reached after experiencing expansion. At this time the economy is in an ideal condition for a country. This peak condition does not last forever but will decrease again. Third, recession is a decline in economic growth. During a recession, the level of output produced by a country will decrease. Next, the fourth stage is the thought where the decline in economic activity will not continue, but will stop at the lowest point (trought). Currently, economic growth is at its lowest point. If economic activity declines sharply and reaches its lowest point beyond the lowest point that usually occurs in the economy, it can be said that the economy is experiencing depression.

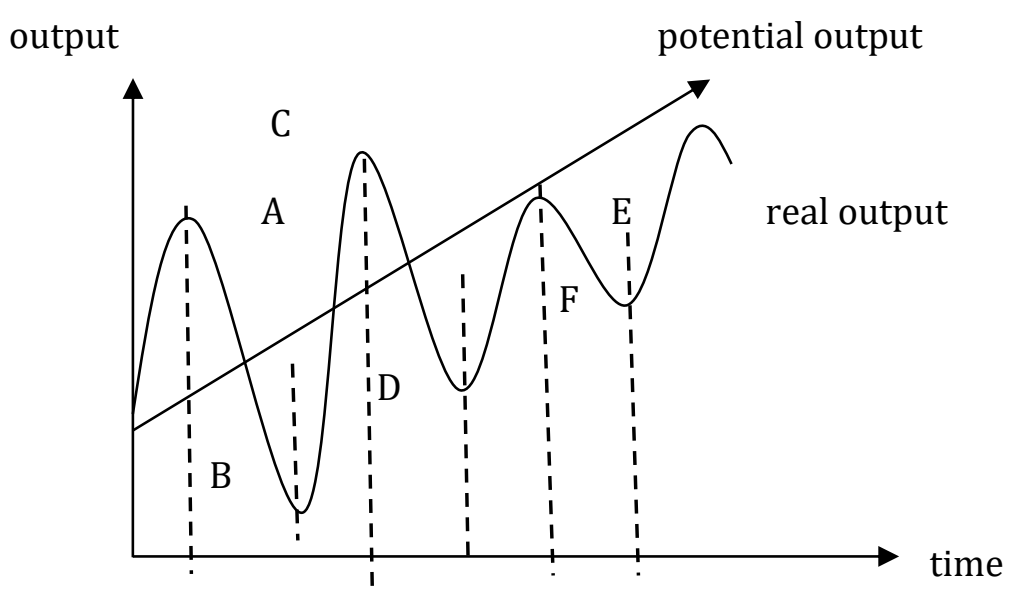

Figure 2. The Stages of the Business Cycle

Points A, C, and E in Figure 2 are economic developments that are at the peak of the boom cycle and economic activity is relatively high compared to the trend, then between point $A$ and point $B$ the economy experiences a recession, as well as between point $C$ and point $D$ and between point $\mathrm{E}$ and point $\mathrm{F}$.

In the research conducted by Canova and Della (1993) in Trade Interdependence and the International Business Cycle, it is explained that in general the role of interconnected trade is moderate and has a stronger position in the period before 1973. business itself and have a fairly close relationship. They discussed data from 1960 quarter 1 to 1986 quarter 2 and created a cycle pattern using the Hodrick-Prescott filter method. The business cycle is an international phenomenon in which economic conditions tend to have a strong correlation between countries. The flow of trade is one of the factors that can be a natural factor in explaining the relationship. 
With this, the discussion related to the flow of trade movements at the international level has become a hot topic to be discussed, especially when it comes to policies that have emerged today.

Prasad (1999) in his research entitled International Trade and Business Cycle using the VAR structural analysis tool examined the G-7 economy and found that there is a conditional relationship between the business cycle and the trade balance caused by different shocks. It is also found that shocks in nominal values have a significant effect on fluctuations in the trade balance in the period after Bretton-Woods.

Research by Julian di Giovanni and Andrei A Levchenko (2010) with the title Putting the Parts Together: Trade, Vertical Linkages, and Business Cycle Comovement again explains this relationship. They found that the countries that traded between them the most showed higher business cycle correlations. International trade at the bilateral level increases the joint movement more significantly. This shows that the existence of trade between countries will connect the economy with one another so that the world economy is no longer small parts but becomes a whole. Especially with the elimination of boundaries between countries for the economy with bilateral and multilateral regulations that are often encountered today.

With this situation and the studies that have been done related to the trade cycle and business cycle as well as existing policies in countries in the world. So in this study, we want to see how far the trade cycle owned by the UK is seen through exports and imports and compared to the business cycle, namely the value of GDP itself. So that later it can be seen the relationship between the global economic situation and the domestic economy in the UK itself.

\section{Research Methods}

This study uses secondary quarter data on exports, imports, and GDP from the UK obtained from the IMF website from 1987 to 2016 . The amount of data used is 120 data. The data was accessed on December 4, 2017. The data obtained will be simplified by performing a natural log and then the filtering method is used to show the cycle of each variable.

Referring to the research of Drehmann et al. (2012), the data filtering method used in this study is the band-pass filter introduced by Christiano and Fitzgerald (2003). This method is used to isolate short-term cycles and assumes the average growth is stationary and there is no trend (drift) (Drehmann et al., 2012). Variables are filtered in the medium term, namely 32 to 80 quarters (8-20 years). The selection of these limits refers to previous studies (Drehmann et al., 2012; Alamsyah et al., 2014).

This study also looks at the relationship between the trade cycle and the business cycle where the business cycle is a form of capital flows for a country starting from capital inflows or capital inflows obtained from exports and capital outflows or capital outflows obtained from 
JAMPE Vol. 1. No 1, January 2022 pp. 9-18

imports. Capital flows in a country are said to be countercyclical if the components of the net capital inflows cycle and the level of output are negatively correlated or in other words the country borrows funds from abroad during recessions (capital inflows) and pays them during the expansion cycle (capital outflows). Capital flows in two countries are said to be procyclical if the cyclical components of net capital inflows with output levels are positively correlated or in other words that the country borrows funds from abroad during expansion (capital inflows) and pays them in times of recession (capital inflows). Meanwhile, capital flows are said to be acyclical if the cyclical components of net capital inflows are not correlated with the level of output. In the following, a summary of the theoretical correlation between capital flows and the business cycle will be presented.

Table 2. Capital Flows: Theoretical Correlation with Business Cycle

\begin{tabular}{|l|c|c|}
\hline & Net capital inflows & Net capital inflows/GDP \\
\hline Countercyclical & - & - \\
\hline Procyclical & + & $+/ 0 /-$ \\
\hline Acyclical & 0 & - \\
\hline
\end{tabular}

Source: Kaminsky et. al (2004)

From table 2 it can be seen the theoretical correlation of the presence of incoming capital and its relationship with the business cycle. To better understand the cyclicality between capital flows and the business cycle, the following will describe an overview of the countercyclical, procyclical, and acyclical forms. The description is as follows:

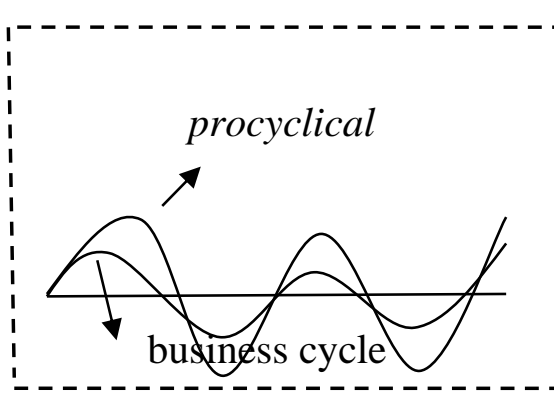

(a)

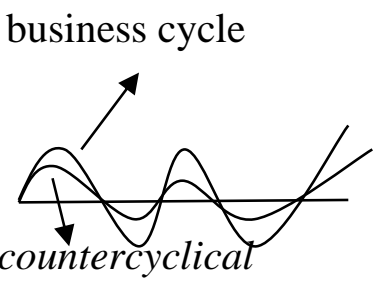

(b)

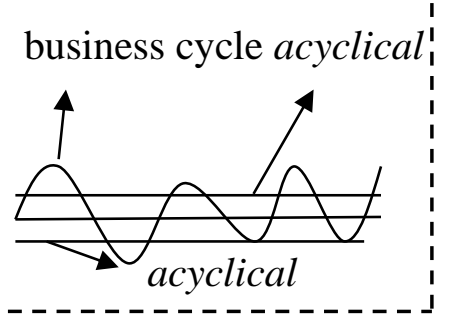

(c)

Figure 3. Cyclicality in Capital Flow and Business Cycle

Capital flows are said to be procyclical when capital flows tend to strengthen the business cycle. It can be seen from Figure 3, that part (a) experienced a higher procyclical movement than the business cycle that occurred. Meanwhile, part (b) can be explained that capital flows are said to be contercyclical when capital flows tend to stabilize the business cycle. This can be seen from the lower countercyclical movement of the business cycle that occurred. As for acyclical, it can be seen from part (c) that capital flows will tend to be unrelated to the business cycle. So in acyclical 
there is a situation where the incoming capital flow is not related to the level of output of a country.

Understanding and distinguishing between the factors that influence macroeconomic fluctuations in the short and long term has become one of the main areas of quantitative macroeconomic research. Lucas (1976) argues that understanding the business cycle is critical to designing appropriate stabilization policies. The term "business cycle" refers to the source of deviations from trends occurring due to the wave-like movement of real economic activity with more than three decades, a large empirical business cycle that has been analyzed with many sophisticated tools to attempt to find the main sources of macroeconomic fluctuations. Kydland and Prescott (1982) and Long and Plosser (1983) were pioneers in the real business cycle approach to economic fluctuations. Despite the unresolved issues, the research has managed to shed light on some of the key empirical regularities of the business cycle. After that research was developed and focused on reducing the driving forces of business cycle fluctuations (Blanchard \& Quah, 1989; Saphiro \& Watson, 1998).

\section{Results and Discussion}

The results of data filtering obtained will be discussed in several stages. First, it will be discussed per variable for the trading cycle by looking at the state of the cycle in time. Second, it will be discussed by combining each existing cycle graph plus the business cycle to explain the relationship between cycles.

The first variable is the export variable from the UK where it is the capital inflow which will be shown in the following graphic image:

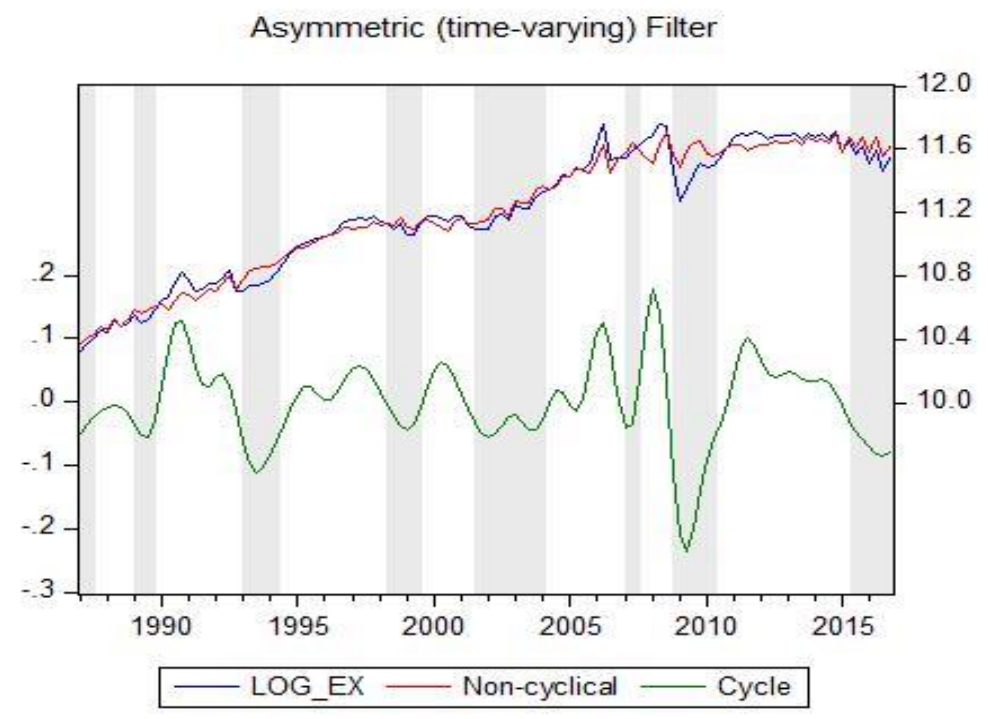

Source: E-Views Results

Figure 4. UK Export Cycle Graph 
From Figure 4. it can be seen how the cycle of exports in the UK is. There have been several recessions as indicated in the gray section. Starting from the first quarter of 1987, then in 1989 there was also a recession and from 1993 to 1994. Then in the 1998 monetary crisis period the recession was also affected, although not too big and then in the early 2000s there was also a decline in exports by the UK. Furthermore, the crisis in 2008 which had many victims, especially in Europe as well as America and the UK, had a significant effect, seen from the decline in the export cycle from that year to the middle of 2009. Then at the end of the research period, British exports also experienced a decline, which was seen from the existing cycle. In the medium term, we can see that there are cycles within 2-4 years that occur in this trade cycle through exports.

Furthermore, other trade variables will be discussed, namely imports from the UK which are capital outflows by looking at the graphic image below:

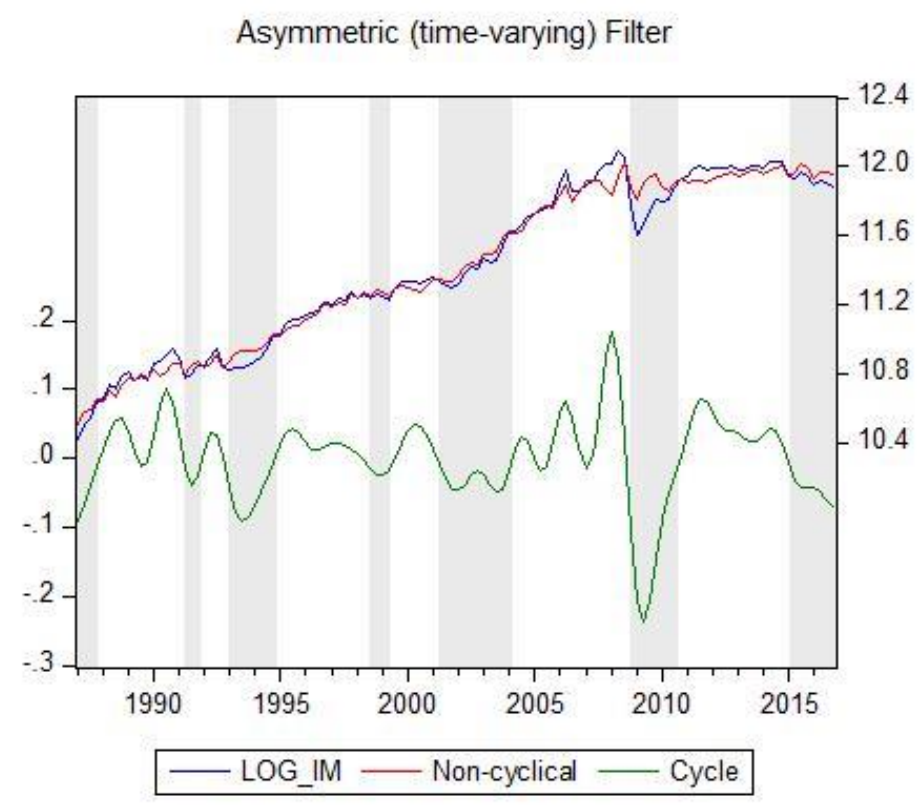

Source: E Views Data Processing Results

Figure 5. UK Import Cycle Graph

If you look at Figure 5. it can be seen that there is a recession or a decline in the import cycle itself. At a glance, the recession experienced by imports is not much different from exports itself. That is at the beginning of the research period in 1987 and 1991. Then added in 1993 to 1994 also experienced a decline. However, during the 1998 crisis, the impact on the trade cycle in the UK itself was not very visible, with a small decline or recession that occurred in the cycle. Then in the early 2000s, there was a fluctuating but relatively low cycle and peaked in late 2008 until the 
2010s caused by the global financial crisis in America and Europe. And towards the end of the research period, the cycle that occurs is also a decline.

The last part of the discussion is a combination of the export and import cycles and the GDP cycle to be able to see the relationship between cycles. The graph can be seen in the following image:

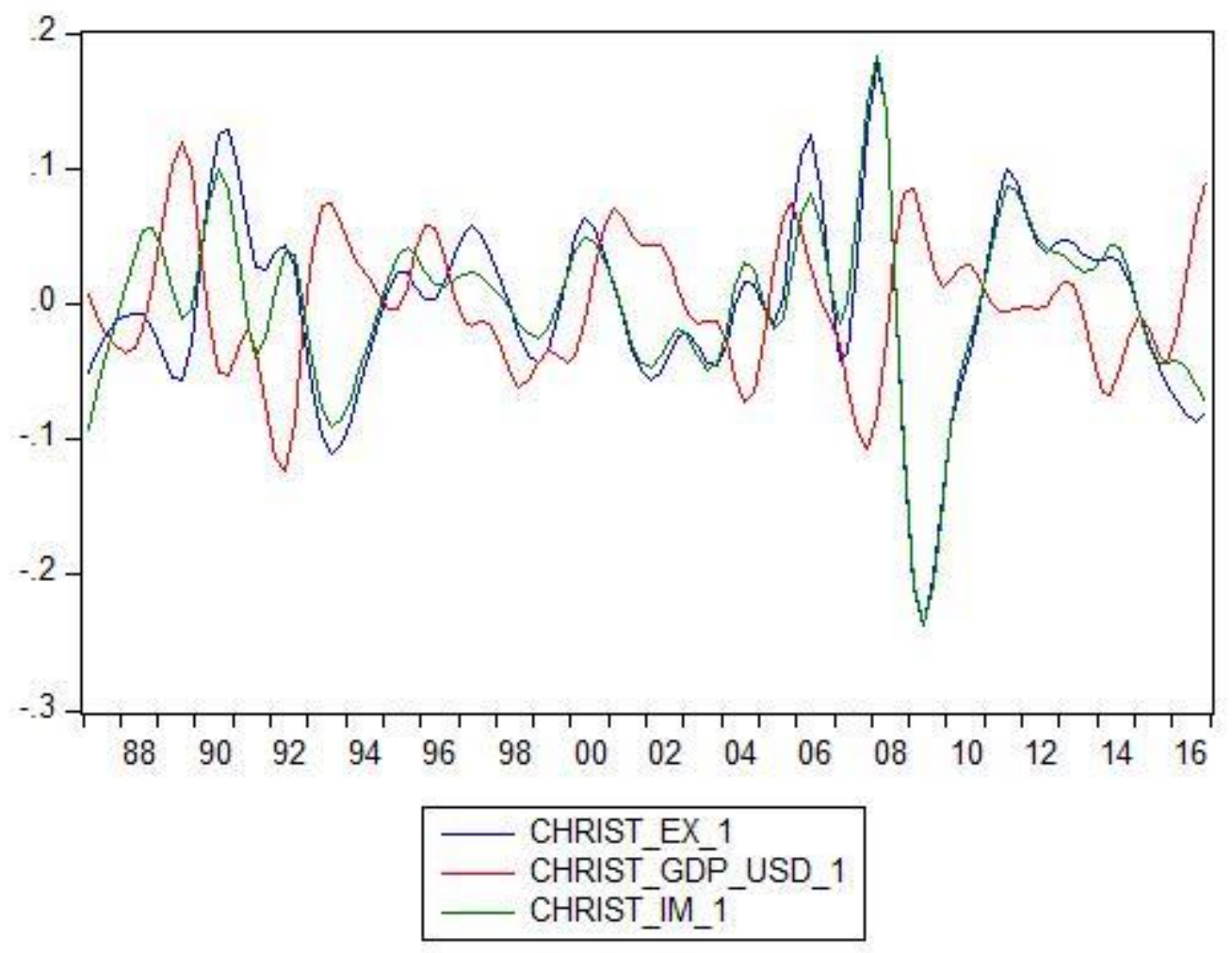

Source: E Views Data Processing Results

Figure 6. Combined Graph of the UK's Export, Import and GDP cycle

It can be seen how the cyclical relationship pattern in the trade cycle through exports and imports with the business cycle in the UK (see Figure 6). If it is seen between the export cycle and the import cycle, it is found that there are many procyclical conditions between the two, although in some circumstances the level of change is different, but basically economic changes in the UK affect the cyclical movement of trade carried out by that country as shown in the blue and green curves shown in Fig. often intersect in the cycle. Meanwhile, if we look at the trade cycle with the business cycle, there are many counter-cyclical situations where the situation between the two cycles is inversely proportional or if one goes up, the other goes down and vice versa. Sometimes we also find an acyclical or unrelated state between the two cycles which shows the lack of a 
relationship between the two. This is quite different from the findings by previous studies where the trade cycle and the business cycle have a close and mutually enhancing relationship.

\section{Conclusion}

From these results we can conclude that the trade cycle in the UK has a medium-term cycle of around 2-4 years for both exports and imports. And there is a significant relationship between global economic events and movements in the trade cycle. Like in the early 2000s and late 2008.

The relationship that exists in the cycle, especially the trade cycle between exports and imports, is found to be procyclical where the conditions are mutually exclusive. Meanwhile, between the trade cycle and the business cycle in the UK, there are many counter-cyclical situations where the relationship between the two cycles is inversely proportional and this is different from the findings of previous studies.

\section{References}

Alamsyah, dkk. (2014). Siklus Keuangan Indonesia. BI Working Paper. WP/8.

Blanchard, Oliver Jean dan Danny Quah. (1989). The Dynamic Effects of Aggregate Demand and Supply Disturbance. The American Economic Review. Vol. 79, No. 4(Sep, 1989). Pp. 655673.

Canova, Fabio dan Harris Dellas. (1993). Trade Interdependence and the International Business Cycle. Journal of International Economics 34, 23-47. North Holland. https://doi.org/10.1016/0022-1996(93)90065-6

Christiano, Lawrence and Fitzgerald, Terry J. (2003). The Band-pass Filter. International Economic Review. Vol. 44 No. 2, pp. 435-465. https://doi.org/10.1111/1468-2354.t01-1$\underline{00076}$

Drehmann, Borio dan Tsarsaronis. (2012). Characterizing the Financial Cycle don't Lose Sight of the Medium Term. BIS Working Paper No. 380.

Giovanni, Julian di dan Andrei A Levchenko. (2010). Putting Parts Together: Trade, Vertical Linkages, and Business Cycle Comovement. American Economic Journal: Macroeconomics 2, 95-124. https://doi.org/10.1257/mac.2.2.95

Kydland, Finn. E dan Edward C. Prescott. (1982). Time to Build and Aggregate Fluctuations. Econometrica. Vol. 50, No. 6, pp. 1345-1370. https://doi.org/10.2307/1913386

Long, John B. Jr. Dan Charles I. Plosser. (1983). Real Business Cycle. Journal of Political Economy. Vol. 91, no. 1. The University of Chicago. https://doi.org/10.1086/261128

Lucas, Robert E, Jr. (1976). Understanding Business Cycle. Kiel Conference, June 22-23, 1976.

Mankiw, N. Gregory. 2006. Makroekonomi. Edisi keenam. Erlangga: Jakarta.

McQueen, Grant dan Thorley, Steven. (1993). Asymmetric Business Cycle Turning Points. Journal of Monetary Economics, 31, 341-362. https://doi.org/10.1016/0304-3932(93)90052-H

Prasad, Eswar S. (1999). International Trade and Business Cycle. The Economic Journal, 109 (October), 588-606. Blackway Publisher. Oxford. https://doi.org/10.1111/1468-0297.00464

Saphiro, Matthew D. Dan Mark W. Watson. (1988). Sources of Business Cycle Fluctuations. NBER Macroeconomics Annual, Volume 3. P. 111-156. MIT Press. https://doi.org/10.1086/654078 
JAMPE Vol 1. No.1 January 2022 pp. 9-18

http://www.bbc.com/news/uk-politics-32810887

http://www.Imf.org/en/data 